\section{The Journey of Insulin: Leaving a Legacy as a Medical Student}

To the Editor,

About the Author: $\operatorname{Dr}$ Ahmad Al-Sukaini is currently a foundation year 1 doctor at Lancashire Teaching Hospitals NHS Foundation Trust. He completed his undergraduate $M B C h B$ at University of Leicester in 2015, where he intercalated and was awarded a Master's Degree in Oncology (Distinc tion) at University of Manchester. He was awarded numerous research prizes, including MCRC bursary, undergraduate elective Prize and BMDST elective re search award. Dr Al-Sukain is also the series adviso of "Clinical Handbook" and has published a number of books including "Rheumatology: A Clinical Handbook".

Submission: Jan 24, 2016 Acceptance: Mar 21, 2016 Publication: Apr 23, 2016 been influential in contributing to medical discoveries and developments. Insulin, heparin, ether anaesthesia and the sino-atrial node are but a mere few of these major findings made by individuals who were once in our very position-as medical students-that have had an enormous impact in the field of medicine. The two inspirational figures that we will discuss in this piece not only left their mark, but they made such an impact during their lives as medical students, that their names will forever remain etched in medicine until the end of time.

During a summer vacation in the year 1867, a young medical student by the name of Paul Langerhans (Figure 1), rather than spending his time in the sun, decided to devote his hours in the laboratory; studying the cell types within the pancreas. A year earlier, he had already displayed his evident talent by staining a sample of human skin with gold chloride and describing the dendritic cells which to this day, bear his name. At this juncture in history, the pancreas had been considered a salivary gland of some type. After many painstaking hours, Langerhans identified a new cell, which scarcely corresponded irregularly polygonal structure. Its cytoplasm is brilliant and free of any granules. Its nucleus distinct, round and moderate size...these cells lie together generally in considerable numbers, diffusely scattered in the substance of the gland". ${ }^{2}$ Langerhans developed a Berlin blue and glycerine mixture for retrograde injection into the pancreatic duct and this exhibited the widely branching collecting system. Intriguingly, his newly discovered cells showed no apparent relation to the duct system. As a result, Langerhans concluded his thesis "I cannot in any way put forth the conclusive results of a completed investigation. I can at most describe a few isolated observations which suggest a much more complicated structure of the pancreas than hitherto accepted." ${ }^{2}$ Langerhans completed his work within six months-the length of a modern medical school research project. It was five years later in fact, that Langerhans' name was attached to these "magic islands" by Edouard Laguesse. The islands were soon described to have an internal secretory activity and these were the first steps in a series of events which led to the discovery of life-sustaining insulin in 1922.

The series of events mentioned that culminated in the discovery of insulin had a degree of symmetry in that the chain began with a medical student (Langerhans) and ended with another medical student by the name of Charles Herbert Best (Figure 2). This student's contribution to medicine brought him within inches of a Nobel Prize. Sir Frederick Banting was the catalyst behind this project. In 1921 he approached John Macleod, a professor of Physiology at the University of Toronto, with the proposal of finding a cure for diabetes mellitus. ${ }^{3}$ The duo recruited Best and a technician-James Collip-to assist with the venture. After a year of tireless work, they discovered "Isletin" (insulin). By late 1921, these academics were able to show the efficacy of insulin in treating canine diabetes. Subsequently not long later, in February 1922, they administered the first insulin injection to successfully treat a fourteen year old diabetic. ${ }^{4}$
Examination of history reveals that medical students have to the concept of a salivary gland." He described a "small,
The Nobel committee awarded the prize only to Banting and Macleod. Aggravated, Banting shared half of his prize money with Best and Macleod half of his with Collip. Later in 1929 Best succeeded Macleod as professor in physiology. ${ }^{3}$

Figure 1. Paul Langerhans (25 July $1847-20$ July 1888 )

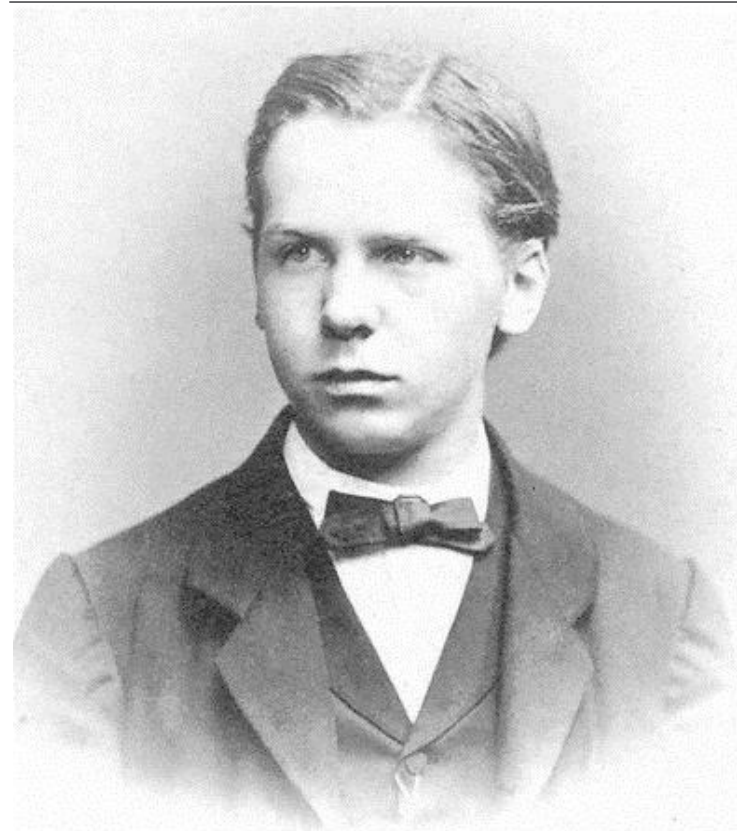

By anonymous. Source: Wikimedia Commons (Available from: https://commons.wikimedia.org/wiki/File:Paul_Langerhans_student.jpg; retrieved 2016 March 9.)

Figure 2. Charles Herbert Best (27 February 1899- 31 March 1978)

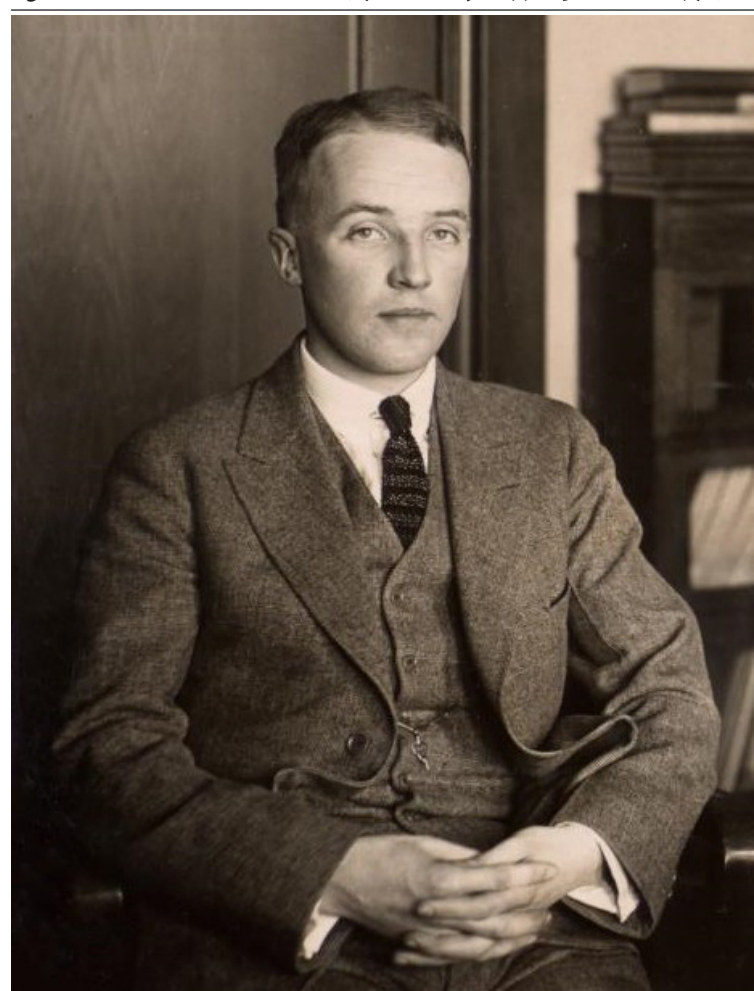

By anonymous. Source: Wikimedia Commons (Available from: https://com mons.wikimedia.org/wiki/File:C. H. Best ca. 1924.jpg; retrieved 2016 March 9.) 


\section{Correspondence}

The pioneering contributions of Paul Langerhans and Charles Best, not to mention countless others, serve as a powerful reminder of what can be achieved as a medical student with a drop of talent and oceans of dedication. These students left their legacies behind along with their shoes, which are waiting to be filled by those of us who are willing. Our medical student experiences and achievements can act as a huge catapult, to propel us into the stratosphere of success.

With medical schools across the world increasingly integrating research projects into their curriculum, it is a golden opportunity for us to both stimulate our intellectual appetites and to contribute towards ongoing medical and professional development. In a conventional five-year journey as a medical student we have 1,825 days, 43,800 hours, 2,628,000 minutes and countless moments in which to strive to create a legacy. With purposeful intentions, strong determination and a desire to succeed, that moment could be within touching distance. Let us reach out and seize it.

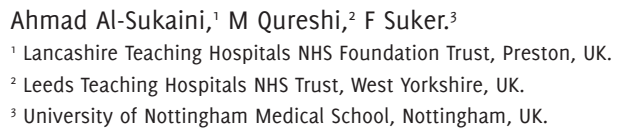

\section{References}

1. Lev E, Ohry-Kossoy K, Ohry A. Langerhans in the Middle East: more about the discoverer of the pancreatic islets. Vesalius. 2003;9:19-21.

2. Morrison H. Contributions to the microscopic anatomy of the pancreas by Paul Langerhans (Berlin, 1869). Reprint of the German original with an English translation and an introductory essay. Bull Hist Med. 1937;5:259-65. 3. Jukes TH. Charles Herbert Best (1899-1978): a biographical sketch. J Nutr. 1980;110(1):18-21.

4. Banting FC, Best CH, Collip JB, Campbell WR, Fletcher AA. Pancreatic extracts in the treatment of diabetes mellitus. Can Med Assoc J. 1922;12(3):141-6.

Acknowledgments: None.

Conflict of Interest Statement at Funding: The authors have no funding, financial relationships, or conflicts of interest to disclose.

Author Contributions: Conceptualization, Writing, Critical revision of the manuscript, Approval of the final version: AAS, MQ, FS.

Cite as: Al-Sukaini A, Qureshi M, Suker F. The journey of insulin: leaving a legacy as a medical student. Int J Med Students. 2016 Jan-Apr;4(1):40-1. 